\title{
The Best Way for Teaching of Occupational and Environmental Carcinogens to Medical Sciences Students
}

\author{
Seyedeh Negar Assadi ${ }^{1 *}$ (D) \\ ${ }^{\mathrm{T}}$ Social Determinants of Health Research Center, Mashhad University of Medical Sciences, Mashhad, Iran \\ ORCID iD: http://orcid.org/0000-0003-3781-2056
}

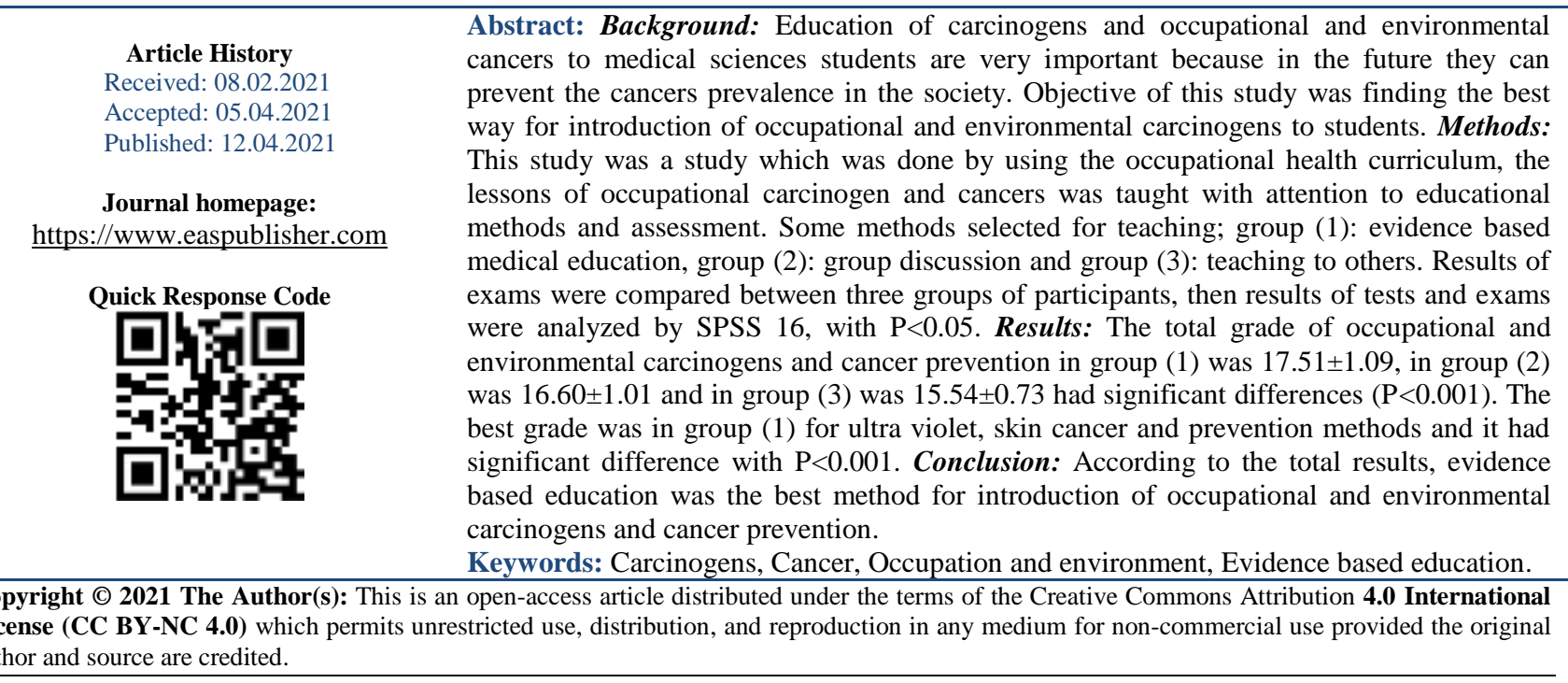

\section{INTRODUCTION}

Medical sciences education has many different methods $[1,2]$. Some researchers studied about the new educational methods for these students [3, 4]. But in some researches were introduced suitable methods for related educational subjects [5].

Evidence based education is a new and suitable one for some lessons, group discussion is a good one and also teaching to others was recommended [6].

In evidence based the introduction of occupational and environmental carcinogens and cancer prevention is an important subject for medical sciences students and can do by using of references [7-9] and new knowledge in scientific websites $[10,11]$.

Some researches recommended methods for teaching in medical sciences [12-14]. One of these methods was group discussion, in this method students were divided to groups and discussed about the subject and they must read before the class and prepared themselves for classes.
Other method was teaching to others, in this method one student read and prepared presentation for teaching other students. All of these were recommended for teaching in medical sciences schools [15-17].

Teaching must be done by using the best method for specific subjects; all of these methods might be not suitable for it [18].

In occupational and environmental carcinogens; there were Silica, Asbestos, aromatic amines, polycyclic aromatic hydrocarbons, Arsenic, Nickel, Chromium, Cadmium, ultra violet, shift work (night work) and Benzene. These caused some cancers such as lung cancer, mesothelioma, bladder cancer, hemangiosarcoma of liver, leukemia, skin cancer, laryngeal cancer, nasal and paranasal sinuses cancer and gastrointestinal cancer. Prevention of them was necessary in the society.

In this study, the author tries to find the best way for introduction of occupational and environmental carcinogens and cancer prevention for education of health students. 
Objective of this study was finding the best way for introduction of occupational and environmental carcinogens to students.

\section{Material ANd Methods}

\section{Study design and setting}

This study was a study in school of health.

\section{Population and sample size}

Occupational health students with random sampling were participated in three educational groups. Each group had 30-35 students.

\section{Inclusion and exclusion criteria}

The inclusion criteria were the health students in entrance year in the field of health and exclusion criteria was studying another field of education.

\section{Implementation of study}

Study was done by using the occupational health curriculum in ministry of health, the lessons of occupational carcinogen and cancers was taught with attention to educational methods.

Three methods selected for teaching; evidence based, group discussion and teaching other. Results of exams were compared between three groups of participants.

Course and lesson plans were written according to educational aim and objectives. In occupational and environmental carcinogens; there were Silica, Asbestos, aromatic amines, polycyclic aromatic hydrocarbons, Arsenic, Nickel, Chromium, Cadmium, ultra violet and Benzene.

Some cancers that caused by these carcinogens were lung cancer, mesothelioma, bladder cancer, hemangiosarcoma of liver, leukemia, skin cancer, laryngeal cancer, nasal and paranasal sinuses cancer and gastrointestinal cancer.

In group (1) the method was evidence based education by using the scientific journals and websites such as international agency for research on cancer [1921].

In group (2) the method was group discussion by dividing the students to groups and in group (3) the method was teaching other and in each session one to two students prepared presentation and teach.

\section{Validity and reliability of tools}

Tests of groups were at the equal levels, these tests and examinations were prepared by teachers' opinions for making sure about the correction and validity and there had been a pilot study with correlation of 0.94 for assigning the reliability in a sample of medical sciences students. These exams were according to educational objectives and plans for occupational and environmental carcinogens and cancer prevention.

\section{Data statistics}

Data were gathered in SPSS 16 and analyzed for calculation of grades means, K-S test was analyzed data, ANOVA was done for normalized data and $\mathrm{P}<0.05$.In research ethics; the researcher got oral consent from participants.

\section{RESULTS}

Mean of age was $22.03 \pm 1.02$ years and $70(77.7 \%)$ were women and $20(22.3 \%)$ were men. (Table1) The total grade of occupational and environmental carcinogens and cancer prevention in group (1) was $17.51 \pm 1.09$, in group (2) was $16.60 \pm 1.01$ and in group (3) was $15.54 \pm 0.73$ had significant differences $(\mathrm{P}<0.001)$.

The best grades were in group 1 for example; for ultra violet, skin cancer and prevention methods and it had significant difference between groups with $\mathrm{P}<0.001$.

Table 2 shows the comparison of grades in occupational and environmental carcinogens lessons between three groups of students. The grade of ultra violet was the best with $0.88 \pm 0.06$ in group 1 .

Table 3 shows the comparison of grades in occupational and environmental cancers and prevention lessons between three groups of students. The grade of Skin cancer was $0.88 \pm 0.15$, laryngeal cancer was $0.88 \pm 0.10$, Hemangiosarcoma of liver was $0.88 \pm 0.06$, and nasal and paranasal cancer was $0.88 \pm 0.05$ in group (1). The difference between mean grades of lessons was significant. $(\mathrm{P}<0.001)$ The total mean was $16.83 \pm 1.04$.

All of the grades differences were significant: Silica, Asbestos, aromatic amines, polycyclic aromatic hydrocarbons, Arsenic, Nickel, Chromium, Cadmium, ultra violet and Benzene were significant with $\mathrm{P}<0.05$.

Grades differences of occupational and environmental cancers and prevention lessons: lung cancer, mesothelioma, bladder cancer, hemangiosarcoma of liver, leukemia, skin cancer, laryngeal cancer, nasal and paranasal sinuses cancer and gastrointestinal cancer were significant with $\mathrm{P}<0.05$. 
Table-1: Demographic and general data

\begin{tabular}{|l|c|c|c|c|}
\hline variable & $\begin{array}{c}\text { Group 1 } \\
\boldsymbol{\mu} \pm \text { SD or } \\
\mathbf{N}(\%)\end{array}$ & $\begin{array}{c}\text { Group 2 } \\
\boldsymbol{\mu} \pm \text { SD or } \\
\mathbf{N}(\%)\end{array}$ & $\begin{array}{c}\text { Group 3 } \\
\boldsymbol{\mu} \pm \text { SD or } \\
\mathbf{N}(\%)\end{array}$ & P \\
\hline Age & $22.02 \pm 0.12$ & $21.65 \pm 1.25$ & $22.10 \pm 0.35$ & 0.54 \\
\hline Gender : Women & $25(83.33)$ & $29(93.33)$ & $29(82.85)$ & 1.00 \\
Men & $5(16.67)$ & $2(6.67)$ & $6(17.15)$ & \\
\hline Average grade & $17.51 \pm 1.09$ & $16.60 \pm 1.01$ & $15.54 \pm 0.73$ & $<0.001$ \\
\hline
\end{tabular}

Table-2: Comparison the grades between three groups of carcinogens lessons.

\begin{tabular}{|l|c|c|c|c|}
\hline Tesson & $\begin{array}{c}\text { Group 1 } \\
\boldsymbol{\mu} \pm \text { SD }\end{array}$ & $\begin{array}{c}\text { Group 2 } \\
\boldsymbol{\mu} \pm \text { SD }\end{array}$ & $\begin{array}{c}\text { Group 3 } \\
\boldsymbol{\mu} \pm \text { SD }\end{array}$ & P \\
\hline Silica & $0.82 \pm 0.15$ & $0.57 \pm 0.08$ & $0.29 \pm 0.03$ & 0.02 \\
\hline Asbestos & $0.80 \pm 0.17$ & $0.53 \pm 0.12$ & $0.29 \pm 0.01$ & 0.01 \\
\hline Aromatic Amines & $0.82 \pm 0.15$ & $0.55 \pm 0.10$ & $0.28 \pm 0.001$ & 0.01 \\
\hline Polycyclic Aromatic Hydrocarbons & $0.83 \pm 0.14$ & $0.57 \pm 0.08$ & $0.28 \pm 0.002$ & 0.02 \\
\hline Arsenic & $0.83 \pm 0.16$ & $0.57 \pm 0.09$ & $0.29 \pm 0.10$ & 0.03 \\
\hline Nickel & $0.83 \pm 0.15$ & $0.57 \pm 0.07$ & $0.29 \pm 0.01$ & 0.03 \\
\hline Chromium & $0.83 \pm 0.12$ & $0.58 \pm 0.06$ & $0.29 \pm 0.01$ & 0.02 \\
\hline Cadmium & $0.83 \pm 0.11$ & $0.57 \pm 0.08$ & $0.28 \pm 0.003$ & 0.02 \\
\hline Ultra violet & $0.88 \pm 0.06$ & $0.59 \pm 0.02$ & $0.28 \pm 0.10$ & $<0.001$ \\
\hline Shift work(night work) & $0.82 \pm 0.01$ & $0.60 \pm 0.24$ & $0.33 \pm 0.65$ & 0.03 \\
\hline Benzene & $0.82 \pm 0.15$ & $0.55 \pm 0.10$ & $0.29 \pm 0.11$ & 0.01 \\
\hline
\end{tabular}

Table-3: Comparison the grades between three groups of cancers lessons.

\begin{tabular}{|l|c|c|c|c|}
\hline lesson & $\begin{array}{c}\text { Group 1 } \\
\boldsymbol{\mu} \pm \text { SD }\end{array}$ & $\begin{array}{c}\text { Group 2 } \\
\boldsymbol{\mu} \pm \text { SD }\end{array}$ & $\begin{array}{c}\text { Group 3 } \\
\boldsymbol{\mu} \pm \text { SD }\end{array}$ & P \\
\hline Lung cancer & $0.82 \pm 0.25$ & $0.58 \pm 0.06$ & $0.30 \pm 0.03$ & 0.03 \\
\hline Mesothelioma & $0.83 \pm 0.14$ & $0.57 \pm 0.11$ & $0.29 \pm 0.01$ & 0.03 \\
\hline Bladder cancer & $0.82 \pm 0.15$ & $0.55 \pm 0.12$ & $0.29 \pm 0.10$ & 0.02 \\
\hline Hemangiosarcoma of Liver & $0.88 \pm 0.06$ & $0.60 \pm 0.08$ & $0.29 \pm 0.02$ & 0.01 \\
\hline Leukemia & $0.82 \pm 0.16$ & $0.56 \pm 0.08$ & $0.30 \pm 0.10$ & 0.03 \\
\hline Skin cancer & $0.88 \pm 0.15$ & $0.60 \pm 0.07$ & $0.29 \pm 0.01$ & $<0.001$ \\
\hline Laryngeal cancer & $0.88 \pm 0.10$ & $0.60 \pm 0.06$ & $0.29 \pm 0.01$ & 0.01 \\
\hline Nasal and paranasal sinuses cancer & $0.88 \pm 0.05$ & $0.60 \pm 0.08$ & $0.30 \pm 0.03$ & 0.02 \\
\hline Gastrointestinal cancer & $0.88 \pm 0.06$ & $0.60 \pm 0.02$ & $0.30 \pm 0.10$ & $<0.001$ \\
\hline
\end{tabular}

\section{DiscuSSION}

According to the results; total grade of occupational and environmental carcinogens and cancer prevention in group (1) was $17.51 \pm 1.09$, in group (2) was $16.60 \pm 1.01$ and in group (3) was $15.54 \pm 0.73$ had significant differences $(\mathrm{P}<0.001)$. The best grade was in group 1 for ultra violet, skin cancer and prevention methods and it had significant difference with $\mathrm{P}<0.001$.

In this article the grades in occupational and environmental carcinogens were the most in group (1) by evidence based education and ultra violet, polycyclic aromatic hydrocarbons, Arsenic, Nickel, Chromium and Cadmium had the best grades. Also grades of skin cancer, hemangiosarcoma of liver, laryngeal cancer, nasal and paranasal cancer and gastrointestinal cancer was the best in group (1) [22, 23]. Other study demonstrated the effects of evidence based education [3]. In this study author try to demonstrate the effectiveness of evidence based medical sciences education for better learning in health students.
Scientists showed the effectiveness of teaching by evidence based education in medical sciences students [4]. In this article the researcher tell about the effectiveness of this method for teaching of carcinogens and cancer prevention.

In some studies were emphasized on using up to date references such as scientific websites and online journals for medical sciences students $[1,2]$. In this study the author tried to introduce the related websites and using them in the class.

Researchers studied about the evidence based education for psychiatry and it's effectiveness [5]. In this study the researcher compare the results of exams for finding the effectiveness of the best method for teaching. 
Studies demonstrated the effect of other educational methods $[1,2]$. In this study the author used other methods in two other groups and found the important results, these might be useful for other lessons.

This study had some limitations; the number of students, another study is recommended with more students and in other field of medical sciences. Use of new knowledge about the risk factors can help the health professions for prevention of exposures and diseases such as cancers, in this situation evidence based education can be the best.

This study recommended using the new knowledge for teaching the occupational and environmental carcinogens and prevention of cancers by using evidence based education.

\section{CONCLUSION}

According to the total results, evidence based education was the best method for introduction of occupational and environmental carcinogens and cancer prevention.

\section{ACKNOWLEDGEMENT}

The author would like to thank the Vice Chancellor for Research of Mashhad University of Medical Sciences for supporting the research project (no 911043) and a lot of thanks from respectful journal.

\section{REFERENCES}

1. Simon, H. (2012). Principles of teaching and learning. http://www.med.fsu. edu/ education/ faculty development/ principles_teach_learn. Asp. Accessed 20 Apr 2012.

2. Tsai, P. S., Tsai, C. C., \& Hwang, G. H. (2016). The effects of instructional methods on students' learning outcomes requiring different cognitive abilities: context-aware ubiquitous learning versus traditional instruction. Interactive Learning Environments, 24(7), 1497-1510.

3. Dornan, T., Littlewood, S., Margolis, S. A., Ypinazar, V., Scherpbier, A., \& Spencer, J. (2007). Identification of best evidence in medical education. Case study. Medical teacher, 29(4), e72e75.

4. Ramstrand, N., \& Brodtkorb, T. H. (2008). Considerations for developing an evidenced-based practice in orthotics and prosthetics. Prosthetics and orthotics international, 32(1), 93-102.

5. McGuckin, C., Burke, D., \& McGuckin, C. (2002). Best evidence medical education in psychiatry training. Australasian Psychiatry, 10(4), 348-352.

6. Patrício, M., \& vaz Carneiro, A. (2012). Systematic reviews of evidence in medical education and clinical medicine: Is the nature of evidence similar?. Medical teacher, 34(6), 474-482.
7. Rugo, H.S., Occupational, Cancer, Ladou, J. (2004). Current Occupational and Environmental Medicine, third edition, Mcgraw-Hill companies, 229-267

8. Hodgson, M. J., \& Addorisio, M. R. (2005). Exposures in indoor environments. In Textbook of clinical occupational and environmental medicine (pp. 1133-1142). WB Saunders.

9. Garte, S.J., Environment Carcinogenesis, Rom , W.N. (2007). Environmental \& occupational medicine, Fourth edition, Lippincott, 137-154

10. IARC. (2017). International Agency for Research on Cancer. http: // www. iarc.fr.htm. Accessed, 20 Apr 2017.

11. IARC. (2017). Monographs - Classification Complete list. http: // www.monographs. Iarc.fr.htm. Accessed 20 Apr 2017.

12. Cullinane, A., \& Liston, M. (2016). Review of the Leaving Certificate biology examination papers (1999-2008) using Bloom's taxonomy-an investigation of the cognitive demands of the examination. Irish Educational Studies, 35(3), 249 267.

13. Kidwell, L. A., Fisher, D. G., Braun, R. L., \& Swanson, D. L. (2013). Developing learning objectives for accounting ethics using Bloom's taxonomy. Accounting Education, 22(1), 44-65.

14. Halawi, L. A., McCarthy, R. V., \& Pires, S. (2009). An evaluation of e-learning on the basis of Bloom's taxonomy: An exploratory study. Journal of Education for Business, 84(6), 374-380.

15. Johnson, D. I., \& Mrowka, K. (2010). Generative learning, quizzing and cognitive learning: An experimental study in the communication classroom. Communication Education, 59(2), 107123.

16. El Kadri, M. S., \& Roth, W. M. (2015). The teaching practicum as a locus of multi-leveled, school-based transformation. Teaching Education, 26(1), 17-37.

17. Barker, D., \& Hapkiewicz, W. G. (1979). The effects of behavioral objectives relevant and incidental learning at two levels of Bloom's taxonomy. The Journal of Educational Research, 72(6), 334-339.

18. Liang, Y. (2015). Responses to negative student evaluations on RateMyProfessors. com: The effect of instructor statement of credibility on student lower-level cognitive learning and state motivation to learn. Communication Education, 64(4), 455471.

19. Workplace safety and health. (2020). National Institute for Occupational Safety and Health. http://www.cdc.gov/niosh. Accessed 20 Apr 2020.

20. Occupational diseases. (2020). Haz-Map. http://www.hazmap.nlm.nil.gov. Accessed $20 \mathrm{Apr}$ 2020. 
21. Safety and health at work. (2020). International Labor Organization, http://www.ilo.org .Accessed 20 Jun 2020.

22. Carcinogens classification. (2020). IARC. http://monographs.iarc.fr /ENG /Classification. Accessed 20 Apr 2020.
23. Cancer sites. http://monographs.iarc.fr/ENG /Classification/Table4.pdf. Accessed 20 Apr 2020.

Cite This Article: Seyedeh Negar Assadi (2021). The Best Way for Teaching of Occupational and Environmental Carcinogens to Medical Sciences Students. East African Scholars J Edu Humanit Lit, 4(4), 179-183. 